\title{
Method of correcting automotive batteries charge periodicity in winter period
}

\author{
Nikolay Stepanovich Zakharov \\ Industrial University of Tyumen, \\ Volodarskogo St., 38, Tyumen, 625000, Russia. \\ sapozhenkovn@mail.ru
}

\author{
Nikolay Olegovich Sapozhenkov \\ Industrial University of Tyumen, \\ Volodarskogo St., 38, Tyumen, 625000, Russia \\ sapozhenkovn@mail.ru
}

\author{
Ruslan Albertovich Ziganshin \\ Industrial University of Tyumen, \\ Volodarskogo St., 38, Tyumen, 625000, Russia \\ sapozhenkovn@mail.ru
}

\begin{abstract}
The problem of a steady power increase of electric equipment on the cars and the need for its daily operation emphasise the relevance of research, aimed at predicting the automotive batteries state of charge in order to ensure reliable starting of the engine at negative temperature. The purpose of the present work is to improve the efficiency of car operation by adjusting the periodicity of batteries charging in winter. On the basis of the research, the scientific and practical task of reducing the costs of vehicle maintenance and repair has been solved by establishing the patterns of formation of the automotive batteries state of charge in winter. And, based on that, a method for correcting the periodicity of their charge has been developed, taking into account the ambient temperature, the intensity of operation and the characteristics of car electrical equipment. The results of the research open up new opportunities for further development of monitoring and forecasting tools of indicators of changing the technical condition of automotive batteries and developing methods to ensure their operability in cold climates, which can serve as a basis for improving the design and reliability of batteries, chargers, electric starters and power supply systems.
\end{abstract}

Keywords-automotive lead-acid battery, state of charge, capacity, temperature change, maintenance

\section{INTRODUCTION}

One of the most important parts of the state transport system is the road transport. With the continuous development of modern technologies, particularly electronics, cars are becoming increasingly saturated with the consumers of electricity. The necessity of their daily operation increases the requirements both for the automotive battery $(\mathrm{AB})$ and for the main source of electric power, which provides the internal combustion engine (ICE) start.

The indicators of the technical condition of the $\mathrm{AB}$ are largely influenced by the characteristics of the $\mathrm{AB}$ itself and the operating conditions. From the point of view of providing optimal charging conditions, cars operation in large cities in winter can be considered as the most unfavorable. Frequent ICE starts in a relatively short period of time, or start-up - a short run - and subsequent long parking at low temperatures are dangerous because the generator does not have enough time to transfer the amount of electricity that the $\mathrm{AB}$ have lost during the previous discharges. Daily operation of $\mathrm{AB}$ in such conditions without additional charge contributes to a rapid state of charge reduction, as a result of which the start of ICE in the cold season deteriorates or does not become possible at all.

The current routine maintenance (RM) system does not fully take into account the effect of conditions and intensity of operation combinations on the $\mathrm{AB}$ state of charge formation. Taking into account the fact that today more than $80 \%$ of innovations in the automotive industry are based on electronics, which indicates a steady trend towards increasing the power of electric consumers, and that a significant part of cars operation territory is located in zones with temperate and cold climate, the research aimed at developing new methods of maintaining the $A B$ performance, the basis on the state of charge patterns to ensure a reliable ICE start and the correct operation of car electrical equipment in winter is relevant.

The purpose of the work is to increase the efficiency of car operation by adjusting the periodicity of charging of $A B$ in winter.

The object of research is the process of forming the state of charge of $\mathrm{AB}$ in winter.

The subject of the research is the patterns of the $A B$ state of charge formation, taking into account the changes in the ambient air temperature and city cars operation intensity in winter.

Theoretical significance of the research consists in establishing patterns and developing models of the $\mathrm{AB}$ state of charge formation for the cars, operated in the city in winter.

Practical value consists in developing the method of correcting $\mathrm{AB}$ charge periodicity, the use of which reduces the costs of carrying out operations for the $\mathrm{AB}$ charge and the costs that arise in the case of an unsuccessful ICE start in the cold climate conditions. 


\section{MethodOLOGY}

The AB state of charge has a significant influence on the indicators of the car's ICE electric starter system.

The low $\mathrm{AB}$ state of charge value decreases the starting frequency of the ICE crankshaft's rotation and reduces the efficiency of the ignition system, which, in view of the deterioration of the fuel-air formation conditions and working mixture ignition at low temperatures, makes starting ICE difficult. Furthermore, if $\mathrm{AB}$ is discharged at negative temperatures while car is parking, the probability of electrolyte freezing increases. In this case, starting ICE becomes impossible, and the $\mathrm{AB}$, as a rule, either loses its capacity or prematurely fails.

Winter operation of cars in the city with low average daily runs does not correspond to the optimal $\mathrm{AB}$ charging conditions. Frequent short distance trips, low average speed and a long time ICE idling cause a reduction of the generator output current in the specified limits of the regulated voltage [3].

At low temperatures, the power and duration of the $A B$ discharge current increase, which is connected with starter and additional electric equipment operation - heating of seats, glass, mirrors, etc. On the contrary, due to the slowing rate of chemical reactions, occurring in lead-acid $\mathrm{AB}$, power of the charging current decreases [13]. Under such conditions, the power supply system does not have enough time to replenish the initial AB state of charge.

The patterns of changing the factors, affecting the state of $\mathrm{AB}$ charge, are studied in the works by Dasoyan M.A. [4], Kwait S.M. [7], Karden E. [6], Jutt V.E. [5], Berndt D. [2], Meissner E. [9], [10], [11] and others. Researchers have noted that in the winter period, the $\mathrm{AB}$ state of charge decreases. In addition to using heating systems and insulation, it was proposed to adjust the periodicity of their charge, to change seasonally the density of electrolyte of $\mathrm{AB}$ in service. Besides, it was suggested installing a higher capacity $\mathrm{AB}$ in conjunction with charge control devices and setting the upper limits of regulated voltage in settings of power supply systems.

The AB charge is carried out from an external source in the framework of RM. However, the periodicity of RM for cars is usually tied to a run (7-20 thousand kilometers) or to a time interval (once per calendar year).

In this case, the $A B$ charge in spring, summer or autumn periods does not allow one to compensate the state of a charge decrease at small car runs in the city during winter. Thus, the $\mathrm{AB}$ can be discharged before the next $\mathrm{RM}$ is scheduled. On the other hand, excessively frequent $\mathrm{AB}$ recharging is economically inexpedient [1].

Monitoring the technical condition and $\mathrm{AB}$ charge are regulated in documents, normalizing the periodicity of RM [8], but the implementation of these operations is accepted to carry out only during RM1, RM2 and seasonal maintenance [14], [15], which does not allow exploring entire operational potential of cars. Moreover, there is no clear rationale for determining the optimal periodicity of performance of $\mathrm{AB}$ charge operations, depending on the design and operational factors.

Determination of optimal periodicity of the $A B$ charge consists in calculating the balance of electric power, taking into account design and power of installed electrical equipment, characteristics of the ICE, periodicity of the car's $\mathrm{RM}$, conditions and intensity of operation. All this allows one to determine the $\mathrm{AB}$ operating time until reaching the critical state of charge, at which the ICE start is difficult.

Thus, this analysis allowed defining the following research problems, which solution allows achieving the goal.

1) to identify the factors, which influence the formation of $\mathrm{AB}$ state of charge during the cars' winter operation in the city;

2) to establish patterns of interaction elements, forming AB state of charge system;

3 ) to develop a simulation model of $\mathrm{AB}$ state of charge formation, taking into account the conditions and intensity of cars winter operation in the city;

4) to develop a method for the practical use of research results and to evaluate its effectiveness.

To meet these challenges, theoretical and experimental studies were conducted.

Selected minimum of costs, related to implementing the operations on $\mathrm{AB}$ charge, and the costs, incurred in the case of ICE failed start, are selected as the objective function of research (Fig. 1).

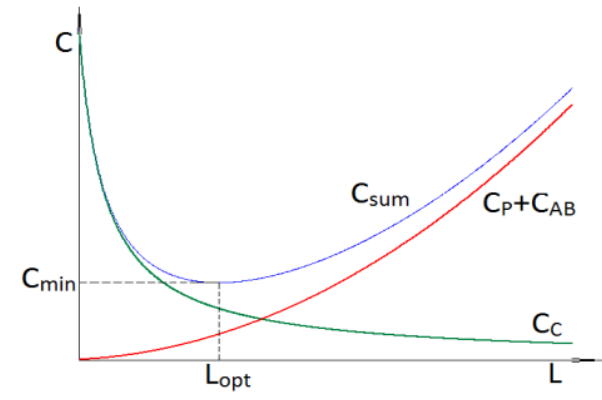

Fig. 1. Objective function

On the one hand, an increase of periodicity of $\mathrm{AB}$ state of charge reduces the maintenance cost per unit. On the other hand, due to the increase of probability of $\mathrm{AB}$ failure during its discharge, such increase in periodicity increases costs per unit, arising in the event of its operability's loss. In this case, the minimum cost of $\mathrm{C}_{\text {sum }}$ will correspond to the optimal $\mathrm{AB}$ charge period, during which the state of charge is sufficient to ensure the ICE start under the current car operating conditions:

$$
C_{\text {sum }}=C_{C}+C_{P}+C_{A B} \rightarrow \min ,
$$

where

$\mathrm{C}_{\mathrm{C}}$ - costs for carrying out $\mathrm{AB}$ charge operations; 
$\mathrm{C}_{\mathrm{P}}-$ costs that arise when ICE fails to start in cold climate conditions;

$\mathrm{C}_{\mathrm{AB}}$ - costs of buying new $\mathrm{AB}$.

The system under study is structured by groups of factors. Inputs of the system are presented in the form of factors and their indicators, which influence the intensity of the running processes, associated with system elements. System output is the optimal AB charge periodicity (Fig. 2).

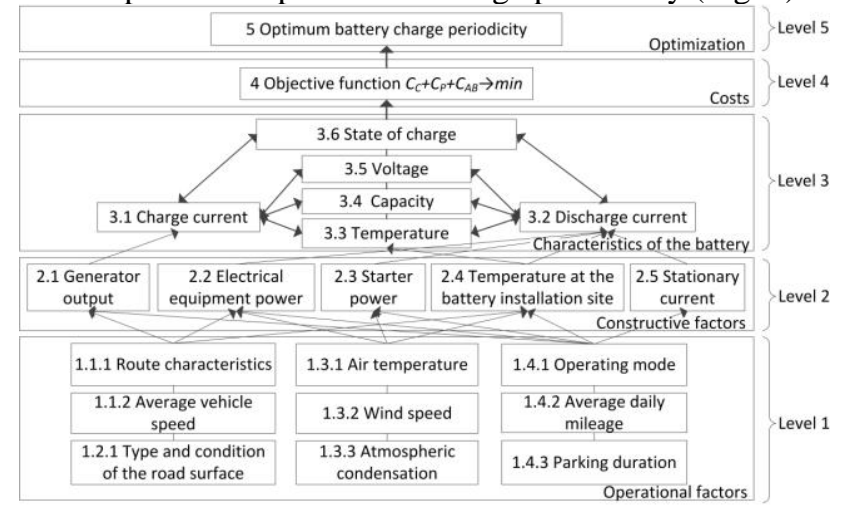

Fig. 2. Enlarged diagram of $A B$ charging formotion system

To evaluate this system further, the patterns of interaction between its elements are examined.

Driving cycles were selected as a basis for modeling the indicators of car operation intensity, due to the fact that they are approved in certification procedures to meet the requirements of environmental standards and fuel efficiency of cars in the city as they are influenced by the same probabilistic factors as the subject of the research.

The efficiency of $\mathrm{AB}$ charge decreases at negative temperatures, which is associated with an electrolyte viscosity's increase, a decrease in the rate of its diffusion into the pores of active material plates and the electrical conductivity reduction. In this connection, based on the previous research [4], [7], a hypothesis about the form of the relative charging current model, depending on electrolyte temperature, voltage and $\mathrm{AB}$ state of charge, is suggested:

$$
I_{3}\left(C_{3}, U, T\right)=y_{0}(T)+\left(\frac{\left(C_{3}-75\right) \cdot\left(y(T)-y_{0}(T)\right)}{25}\right)+(U-14) \cdot\left(Y_{0}(T)-y_{0}(T)\right)
$$

where

$\mathrm{I}_{3}$ - relative $\mathrm{AB}$ charging current, $\mathrm{mA} / \mathrm{Ah}$;

$\mathrm{C}_{3}-\mathrm{AB}$ state of charge, $\%$;

$\mathrm{U}$ - charge voltage, $\mathrm{V}$;

$\mathrm{T}-\mathrm{AB}$ temperature, ${ }^{\circ} \mathrm{C}$;

$\mathrm{y}_{0}(\mathrm{~T}), \mathrm{y}(\mathrm{T}), \mathrm{Y}_{0}(\mathrm{~T})$ - functions interpolating discrete values of relative $\mathrm{AB}$ charge current depending on temperature.

The change of the current strength of equipment during short-term operation conditions in winter is characterized by the fact that in the initial period after the ICE start, there is the need for intensive blowing of the windows and rapid warming-up of the passenger compartment for drive starting. In this case, the current of electric equipment reaches the maximum values, and, as the passenger compartment warms up, the current strength decreases to steady values, corresponding to a long-term operation in a given mode.

In this regard, there was a hypothesis offered about a type of the model of dependence of equipment current strength on ambient temperature:

$$
I_{p}\left(I_{0}, T, t\right)=I_{0}+\frac{D I(T)}{\pi} \cdot \arctan \left(\frac{t+c T}{a}-b\right),
$$

where

$\mathrm{I}_{\mathrm{p}}$ - total current of electric equipment, $\mathrm{A}$;

$\mathrm{I}_{0}$ - current of main electric equipment, $\mathrm{A}$;

$\mathrm{T}$ - ICE temperature before starting, ${ }^{\circ} \mathrm{C}$;

$\mathrm{t}$ - ICE operating time after start, min;

$\mathrm{DI}(\mathrm{T})$ - function that determines the feature of electric equipment current changes;

a, b, c-empirical coefficients.

Depending on the climate performance, cars can be equipped with $\mathrm{AB}$ of different capacities, on which the numerical values of its thermal state indicators depends. Considering the fact that, with other things being equal, the $\mathrm{AB}$ of different capacities will have different characteristics of heating and cooling. A hypothesis has been put forward on the type of the model, describing the dependence of the rate of temperature change of $\mathrm{AB}$ on the capacity and wind speed:

$$
t_{R}\left(C_{20}, V_{t r}\right)=t_{R}\left(V_{t r}\right) \cdot\left(\frac{60}{C_{20}}\right) \cdot \frac{2 \cdot w+2 \cdot l \cdot\left(\frac{C_{20}}{60}\right)}{w+l},
$$

where

$t_{R}$ - rate of $A B$ temperature change;

$t_{R}\left(V_{t r}\right)$ - dependence of the $A B$ cooling rate on the wind speed (under hood installation);

$\mathrm{C}_{20}-\mathrm{AB}$ capacity, Ah;

w, 1 - width and length of $A B$ monoblock wall, meters.

In accordance with the structure of the study system and the adopted regulations, the algorithm of the model of formation of the $\mathrm{AB}$ charge level, when operating city cars in winter, is designed (Fig. 3). 


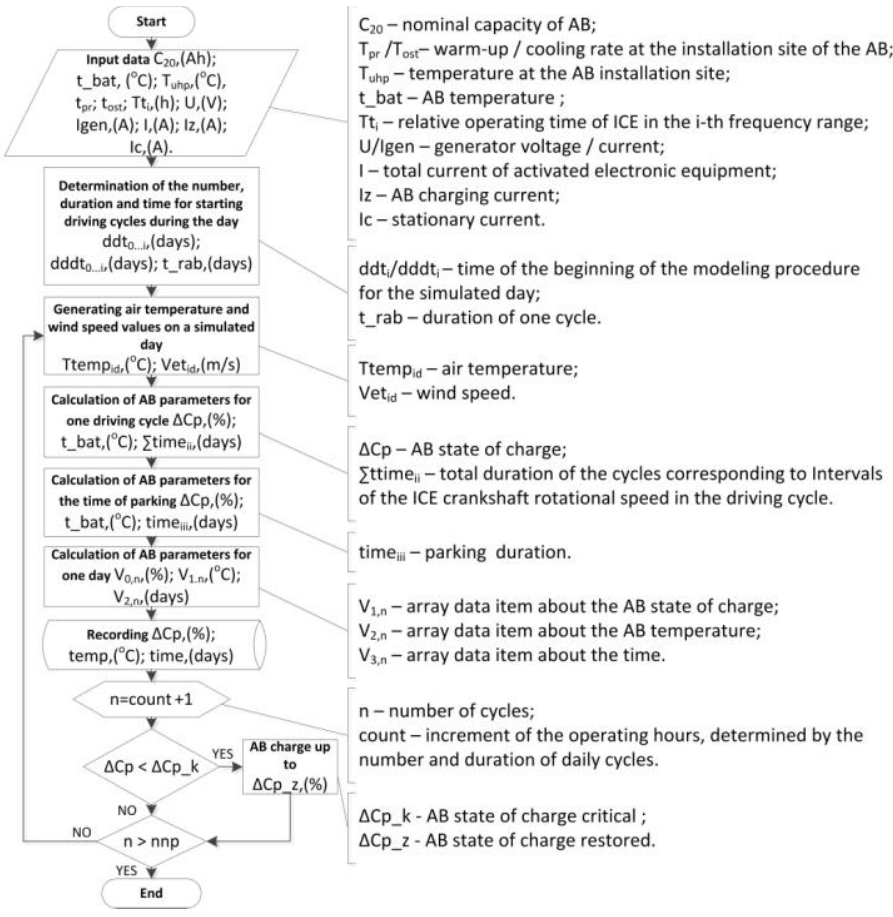

Fig. 3. Enlarged algorithm of simulation model of formation of state of AB charge

A cyclic procedure was written to construct the basic algorithm, which performs the calculation of $\mathrm{AB}$ state of charge and temperature, taking into account ambient air temperature, wind speed, car construction and its mode of use. The specified procedure returns final values of $A B$ state of charge $(\Delta \mathrm{Cp}), \mathrm{AB}$ temperature (temp), end of the cycle time (time) and allows to determine the moment of critical state of charge reaching $\left(\Delta \mathrm{C} \_\mathrm{z}\right)$.

Experimental studies included the following stages:

- determining the numerical values of car operation indicators to develop recommendations for correcting $\mathrm{AB}$ charge periodicity;

- collecting data during the car motion in the urban driving cycle and during the car parking at low ambient temperatures;

- determining the numerical values of parameters of mathematical models, describing the processes of formation of $\mathrm{AB}$ state of charge;

- Simulation of formation processes of $\mathrm{AB}$ state of charge, describing cars' winter operation in the city, checking the adequacy of the hypotheses.

At the first stage, the following data were collected: actual data values of the ambient temperature, wind speed, intensity of operation and quantity of $\mathrm{AB}$ technical impacts. During active experiments in driving cycle conditions on Hyundai Solaris cars, numerical values of parameters of mathematical models were determined. Then, active experiments on the simulation model were conducted.
As a result of the collected statistics, it was established that for more than $30 \%$ of the cars serviced by an official dealer in Tyumen, the average mileage is less than 15 thousand kilometers per year (Fig. 4).

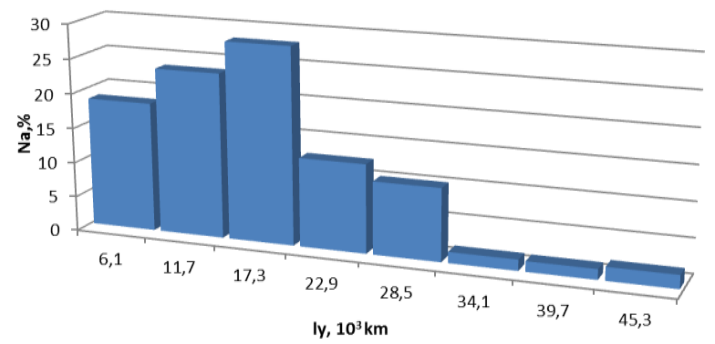

Fig. 4. Distribution of average annual mileage of Hyundai Solaris (1130 units)

With daily use and an average speed of $25 \mathrm{~km} / \mathrm{h}$ in the city, the operating time of such cars within a day does not exceed 2 hours.

At the same time, the greatest number of $A B$ technical actions is observed in the period from November to March, which is associated with a decrease in the ambient temperature during these months, and with a decrease in the $\mathrm{AB}$ state of charge and a deterioration in ICE starting qualities (Fig. 5).

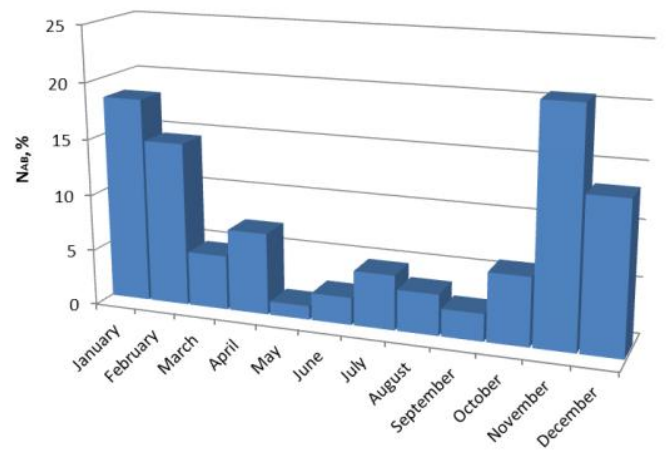

Fig. 5. Variation in quantity of technical impacts on $A B$

During the experimental studies on the car, the values of starting current and the duration of the starter operation, the current of electrical equipment and generator output power, the temperature of ICE oil and coolant, $\mathrm{AB}$ temperature, the frequency of ICE crankshaft rotation and car speed were recorded.

According to the obtained data, numerical values of car's operating characteristics and calculations of a relative generator operating time in ranges of ICE crankshaft rotation, frequencies were determined (Fig. 6). 


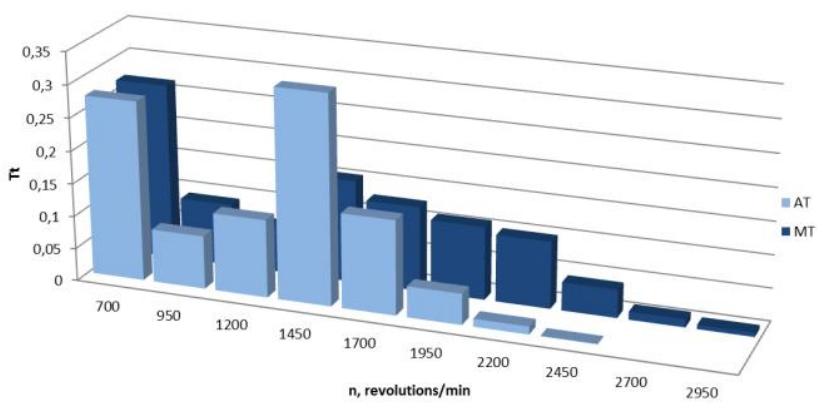

Fig. 6. Distribution of generator relative operating time in frequency ranges of ICE crankshaft's rotation when Hyundai Solaris is moving in the urban driving cycle

This information was used in simulation experiments.

Subsequent processing of the experimental data confirmed previously proposed hypotheses and made it possible to obtain the following models of formation of $\mathrm{AB}$ state of charge (Fig. 7, 8, 9)

$$
\begin{gathered}
t_{\text {ost }}=-\left(\left(1 \cdot 10^{-23}\left(4,378 \cdot 10^{21} \cdot e^{-0,2 V t r}-9,973 \cdot 10^{21}\right)\right) / C_{20}\right)- \\
0,00107 \cdot e^{-0,2 V t r}+0,00248
\end{gathered}
$$

$I_{p}=2,95 \cdot \arctan \left(-0,063 \cdot T_{\theta}-0,01\right)+3,26 \cdot \arctan \left(1,5-0,2 \cdot t_{a s}-0,18 \cdot T_{\theta}\right)+$ $1,85 \cdot \arctan \left(-0,063 \cdot T_{\sigma}-0,01\right) \cdot \arctan \left(1,5-0,2 \cdot t_{a s}-0,18 \cdot T_{s}\right)+25,13 ;$

(6)

$I_{3}=90 \cdot U-47,68 \cdot T-3,4 \cdot C_{3}+52,39 \cdot 10^{-3} \cdot T_{6}^{2} \cdot U+1,73 \cdot 10^{-3} \cdot T^{3} \cdot U+220,14 \cdot 10^{-6} \cdot T^{4} \cdot U+$ $6,54 \cdot 10^{-6} \cdot T^{5} \cdot U+59,72 \cdot 10^{-9} \cdot T^{6} \cdot U-308,56 \cdot 10^{-3} \cdot T^{2}-26,54 \cdot 10^{-3} \cdot T^{3}-2,39 \cdot 10^{-3} \cdot T^{4}-$ $46,92 \cdot 10^{-6} \cdot T^{5}-213,89 \cdot 10^{-9} \cdot T^{6}-223,87 \cdot 10^{-3} \cdot C_{3} \cdot T+5,01 \cdot T \cdot U-4,25 \cdot 10^{-3} \cdot C_{3} \cdot T^{2}+$ $23,33 \cdot 10^{-6} \cdot C_{3} \cdot T^{3}-6,89 \cdot 10^{-6} \cdot C_{3} \cdot T^{4}-446,67 \cdot 10^{-9} \cdot C_{3} \cdot T^{5}-6,22 \cdot 10^{-9} \cdot C_{3} \cdot T^{6}-915$.

(7)

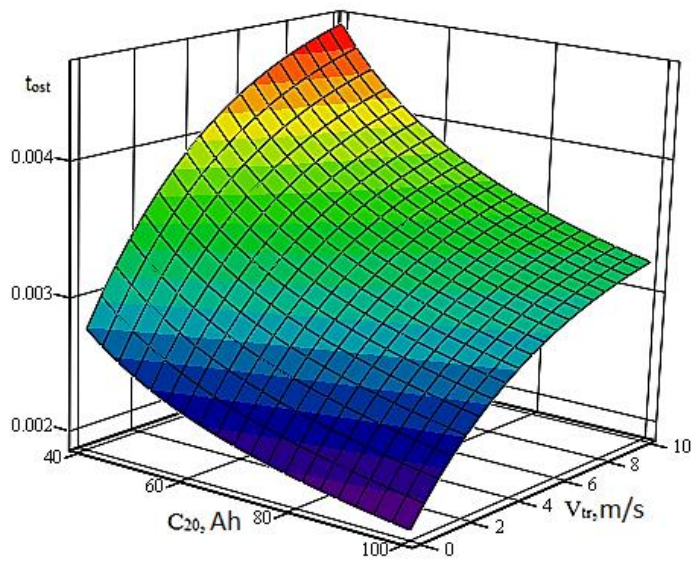

Fig. 7. Influence of wind speed and $A B$ capacity on $A B$ cooling rate

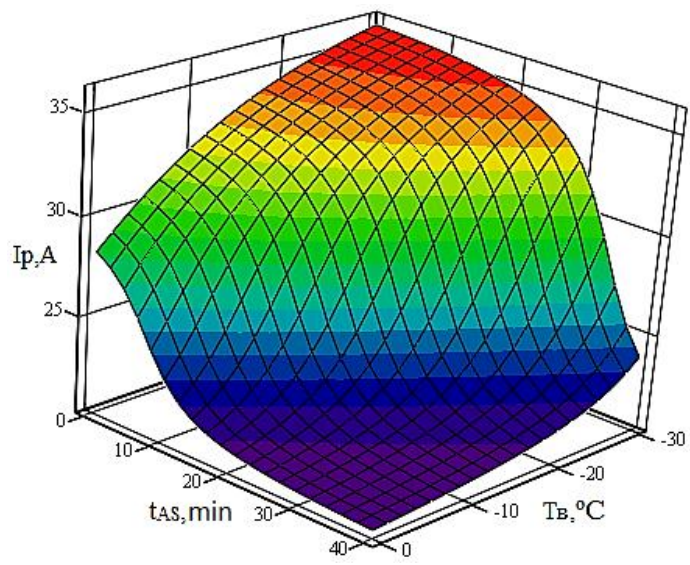

Fig. 8. Influence of ambient temperature and car's running time after ICE starting on the current strength of equipment of long-term action

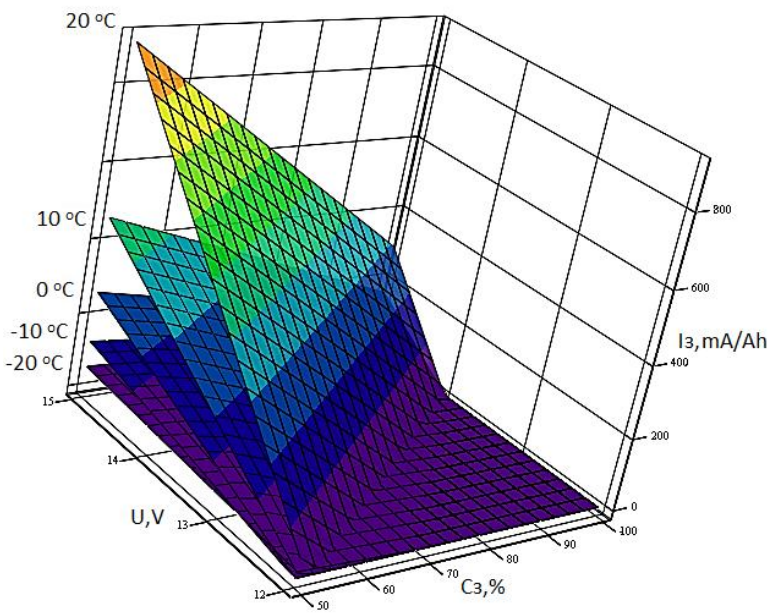

Fig. 9. Influence of $\mathrm{AB}$ state of charge, temperature and charge voltage on the $\mathrm{AB}$ relative charging current

According to the results of simulation, the regularities of formation of $\mathrm{AB}$ state of charge and operating time to failure depending on ambient temperature and car average daily run are set (Fig. 10, 11)

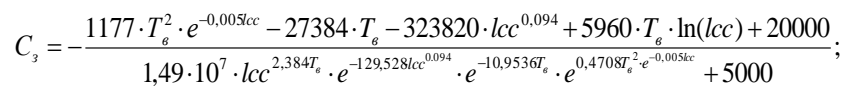

$T_{c r}=\frac{11,09 \cdot l c c+87,56 \cdot T_{s}+4 \cdot l c c^{1.038} \cdot T_{s}+16,49 \cdot l c c^{1,038} \cdot \ln (l c c)-61,59 \cdot l c c^{1,038}+0,51 \cdot l c c^{2,038}+1200}{l c c^{1.038} \cdot(0,13 \cdot l c c+T+10,62)}$. 


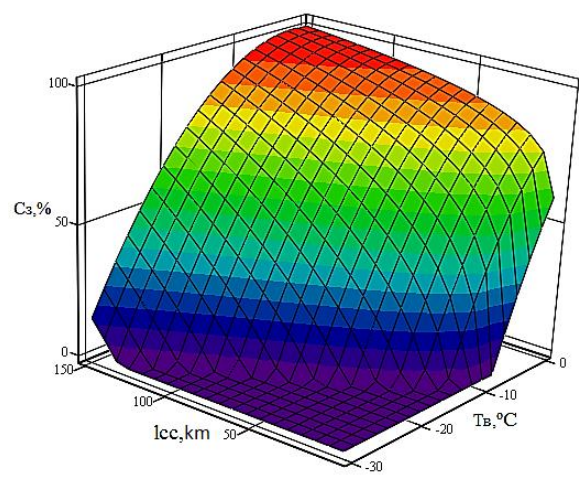

Fig. 10. Influence of ambient temperature and car average daily run on the $\mathrm{AB}$ state of charge $\mathrm{C}_{3}$

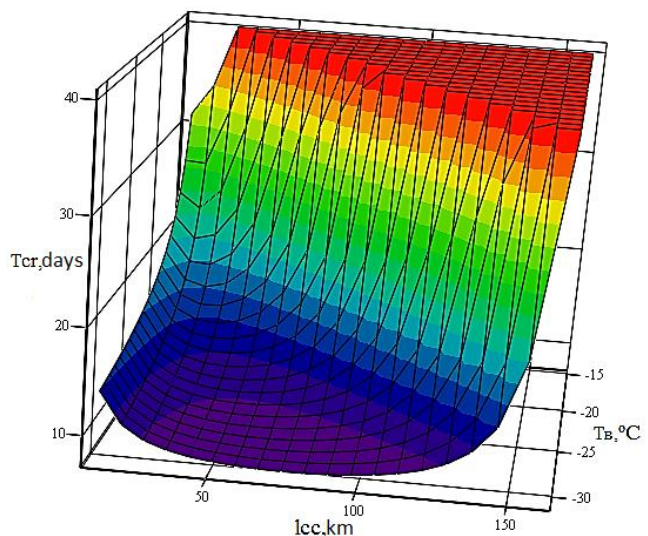

Fig. 11. Influence of ambient temperature and car average daily run on $A B$ operating time to failure Tcr

Fisher criteria showed that mathematical models are adequate with a probability of more than 0.9 . The average error of approximation does not exceed $13 \%$.

\section{OUTCOMES}

This section presents the ways of practical use of the research outcomes. The method of correcting $A B$ charge periodicity is based on simulation models of forming $A B$ state of charge, as software, implemented in the Mathcad 15 , and the results, obtained during experimental studies (Tab. 1)

TABLE I. CHANGING AB STATE OF CHARGE AND OPERATING TIME TO FAILURE DURING CAR OPERATION IN CITY DEPENDING ON AMBIENT TEMPERATURE AND AVERAGE DAILY RUN

\begin{tabular}{|c|c|c|c|c|c|c|c|c|c|c|}
\hline \multirow{2}{*}{$\begin{array}{l}\text { Tв, } \\
{ }^{0} \mathrm{C}\end{array}$} & \multicolumn{10}{|c|}{ Average daily run lcc, km } \\
\hline & 5 & 10 & 20 & 30 & 40 & 50 & 60 & 70 & 80 & 90 \\
\hline 0 & $71^{\mathrm{a}}$ & 76 & 82 & 85 & 87 & 90 & 91 & 93 & 94 & 95 \\
\hline-5 & 48 & 57 & 67 & 73 & 77 & 81 & 84 & 86 & 89 & 91 \\
\hline-10 & 13 & 26 & 41 & 51 & 58 & 63 & 68 & 72 & 75 & 79 \\
\hline-15 & $28^{\mathrm{b}}$ & 25 & 31 & 18 & 28 & 36 & 43 & 49 & 55 & 59 \\
\hline-20 & 23 & 17 & 14 & 14 & 15 & 17 & 23 & 18 & 26 & 33 \\
\hline-25 & 22 & 15 & 12 & 10 & 10 & 10 & 10 & 11 & 12 & 14 \\
\hline
\end{tabular}

Visualization of simulation results allows one to track the dynamics of changing $\mathrm{AB}$ state of charge during the winter period and to take measures to prevent its discharge (Fig. 12).

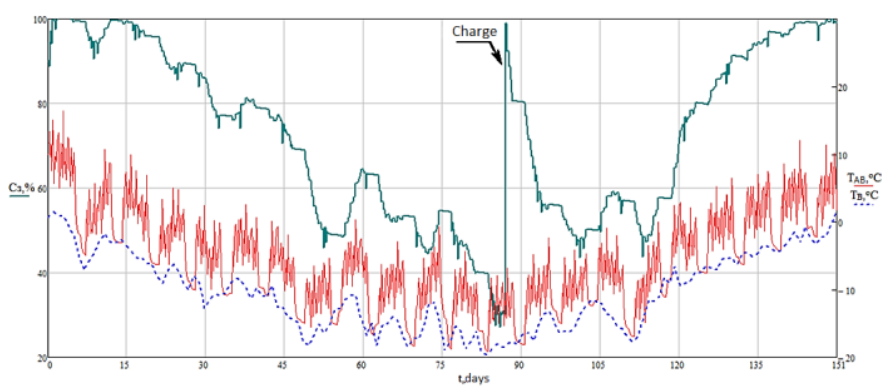

Fig. 12. Modeling of AB state of charge and temperature by the example of Hyundai Solaris's operation in the period from November to March in Tyumen: $\mathrm{C}_{3}-\mathrm{AB}$ state of charge, $\%$; $\mathrm{T}_{\mathrm{Ab}}-\mathrm{AB}$ temperature, ${ }^{\circ} \mathrm{C} ; \mathrm{T}_{\mathrm{B}}-$ ambient temperature, ${ }^{\circ} \mathrm{C}$

The use of method allowed one to develop recommendations for determining $\mathrm{AB}$ charge periodicity for three representative points of climatic regions of the country: Moscow, Tyumen and Salekhard - moderate, moderate-cold and cold climates, accordingly. Operation during the week was presented by 2-day, 5-day and everyday use of the car with open storage for various average daily runs, taking into account the average operating speed during the entire winter period from November to March.

The minimum range value of $\mathrm{AB}$ state of charge is proposed to limit by the temperature at which the electrolyte solution in $\mathrm{AB}$ freezes, as a result of which the ICE start becomes impossible.

Being as a working model, $\mathrm{AB}$ was assumed to be able to withstand two bits before achieving a critical state of charge, and after the third bit, it requires replacement in view of the critical drop of capacity because of irreversibility of degradation processes of electrodes' paste bloating and their warping when the electrolyte solution freezes.

To reduce the costs on implementing $A B$ charge operations, recommendations for increasing the warm-up time before starting the car and selection of the optimum $\mathrm{AB}$ capacity for different intensity of operation are proposed (Table 2).

When operating in cold climate conditions, the estimated economic effect from the introduction of the method can amount to 9350 rubles per car in the winter period. 
TABLE II. RECOMMENDED PERIODICITY OF AB CHARGE ACCORDING TO THE VOLUME OF CAPACITY AND OPERATING MODE OF CAR IN CLIMATIC CONDITIONS OF TYUMEN

\begin{tabular}{|c|c|c|c|c|}
\hline \multirow{2}{*}{$\begin{array}{c}\text { AB } \\
\text { capa } \\
\text { city, } \\
\text { Ah }\end{array}$} & $\begin{array}{c}\text { Average } \\
\text { duration of } \\
\text { one trip, } \mathbf{h}\end{array}$ & \multicolumn{2}{|c|}{ Periodicity of charge for operating mode } \\
\cline { 3 - 5 } & $\mathbf{7 - d a y}$ & $\mathbf{5 - d a y}$ & $\mathbf{2 - d a y}$ \\
\hline 60 & 0.3 & $\begin{array}{c}\text { Every 16 days } \\
\text { from 10.01 to } \\
30.01\end{array}$ & $\begin{array}{c}1 \text { time from } \\
15.01 \text { to } \\
20.01\end{array}$ & $\begin{array}{c}1 \text { time from } \\
20.01 \text { to } \\
25.01\end{array}$ \\
\hline 60 & 0.5 & $\begin{array}{c}1 \text { time from } \\
15.01 \text { to } \\
20.01\end{array}$ & $\begin{array}{c}1 \text { time from } \\
20.01 \text { to } \\
25.01\end{array}$ & $\begin{array}{c}1 \text { time from } \\
25.01 \text { to } \\
01.02\end{array}$ \\
\hline 60 & $0.5+(0.15$ & not required & not required & not required \\
\hline 70 & 0.5 & not required & not required & not required \\
\hline
\end{tabular}

\section{DISCUSSION}

The conducted analysis, analytical and experimental studies have led to the following conclusions.

Frequent ICE starts and increased power consumption of additional electric equipment in unstable urban traffic modes at negative temperatures slow down the replenishment of charge and contribute to the reduction of $\mathrm{AB}$ state of charge, which is the reason for deterioration of ICE starting qualities and incorrect operation of electronic systems. Untimely $\mathrm{AB}$ charge not only leads to deterioration in its operating performance, but also can lead to inability of the car to do useful work for its intended purpose.

At the same time, regular performance of work on control of $\mathrm{AB}$ technical condition requires additional costs and may not be justified due to overly frequent implementation. Based on the research results, we have confirmed the hypothesis about existence of optimal $\mathrm{AB}$ charge periodicity that meets the minimum total costs associated with the planned works on the implementation of $\mathrm{AB}$ technical condition control and charge and measures for restore operability of car, required in the case of ICE failed start.

It was found that the optimal $\mathrm{AB}$ charge changes depending on several factors. The balance in the power supply system is disrupted, on the one hand, due to the charging current decrease, as $\mathrm{AB}$ is cooled, and to the reduction of generator output power at low ICE speeds of the crankshaft rotation. And, on the other hand, this happens because of the increase of energy consumption by the starter and additional electric equipment at the initial moments of motion.

At the same time, construction performance of cars has a significant impact on $\mathrm{AB}$ operation due to differences in $\mathrm{AB}$ capacity, circuit design of the generator and power of installed electrical equipment.

Nevertheless, studies show that, to ensure the required $\mathrm{AB}$ state of charge at low intensity of operation and negative ambient temperature throughout the winter period, an additional charge is required, because it can not be provided in planned RM due to the limited fixed service interval. Monitoring $\mathrm{AB}$ state of charge, based on established patterns, transforming it into the developed simulation model and describing the mechanism of considered factors influence allow one not only to determine the charge requirement and the moments of its carrying out, but also to select the $\mathrm{AB}$ capacity and the optimal warm-up time before start of the movement, which allows reducing the costs of car operation.

It is obvious that such dependencies may be used to determine the timing and content of the technical impacts' list for other vehicles RM. Similar results may be obtained for engineering industries and construction.

Two variants of using the results are proposed. The first option is the use of research-based recommendations for car owners and service companies. The second option involves using the simulation model created in the Mathcad to calculate periodicity of charge, taking into account specific conditions and intensity of operation.

\section{CONCLUSION}

1. On the basis of the research, the scientific and practical task of increasing efficiency of cars operation has been solved by adjusting the periodicity of $A B$ charge, taking into account the conditions and intensity of cars' winter operation in the city.

2. The most significant factors, affecting the formation of $\mathrm{AB}$ state of charge in winter, were identified. It was shown that the ambient temperature and the intensity of car operation determine the ratio between the $\mathrm{AB}$ charging and discharging current and have the greatest influence on the formation of $\mathrm{AB}$ state of charge. Patterns were established, and mathematical models of the processes of formation of $\mathrm{AB}$ state of charge during the cars' operation in winter in the city are developed.

3. A simulation model of formation of $A B$ state of charge was developed, taking into account the conditions and intensity of cars winter operation in the city. Fisher criteria showed its adequacy with the probability of not less than 0.90 . The form of two-factor mathematical models of ambient temperature and influence of average daily run on $\mathrm{AB}$ state of charge and operating time to failure were established.

4. Based on the established patterns, a method of correcting $\mathrm{AB}$ charge periodicity was developed, taking into account the characteristics of electrical equipment installed on the car, the intensity of operation and the ambient temperature, the use of which reduces costs that arise in the event of $\mathrm{AB}$ failure in cold climate conditions. Recommendations for definition ICE warm-up time and selection of $\mathrm{AB}$ capacity for cars were developed and scientifically substantiated. Implementation of the recommendations reduced the cost of performing $\mathrm{AB}$ charge operations.

5. The economic effect of introducing the results of the current research was achieved by reducing the total costs, consisting of the cost of $\mathrm{AB}$ charging, the cost of 
buying new $\mathrm{AB}$ and the costs that arise in the event of unsuccessful ICE start.

\section{References}

[1] V.I. Bauer, E.S. Kozin, A.V. Bazanov, M.V. Nemkov, A.A. Mukhortov, "The methodic of forming a rational structure of a distributed production base of transport divisions in the pipeline industry," Biosciences Biotechnology Research Asia, Vol. 11, pp. 287-295. , 2014

[2] D. Berndt, "VRLA batteries, advances and limitations", Journal of Power Sources, vol. 154, pp. 509-517, 2006.

[3] Dambrowski, J. About the challenges for charging techniques with lead-acid batteries in the automotive industry, R\&D Department. Germany, 2009, p. 16

[4] M.A. Dasoyan, I.A. Aguf, "Bases of calculation, designing and technology of lead accumulators production," Energia, 1978, p. 152.

[5] V.E. Jutt, Electrical equipment of cars, Textbook for High Schools, 2006, p. 440.

[6] E. Karden, P. Shinn, P. Bostock, J. Cunningham, E. Schoultz, D. Kok, "Requirements for future automotive batteries," Journal of Power Sources, vol.144(2), pp. 505-512, 2005.

[7] S.M. Kwait, Y.I. Mendelevich, Y.P. Chizhkov, Starting qualities and launch systems for automotive engines, Moscow: Mechanical Engineering, 1990, p. 256.

[8] E.S. Kuznetsov, Management of technical maintenance of vehicles,. Moscow: Transport, 1990, p. 272

[9] E. Meissner, G. Richter "Vehicle electric power systems are under change Implications for design, monitoring and management of automotive batteries, " Journal of power sources, 95(1-2), pp. 13-23, 2001.

[10] E. Meissner, G. Richter "Battery monitoring and electrical energy management prediction for future vehicle electric power systems," Journal of Power Sources, v. 116 (1-2), pp. 79-98, 2003.

[11] E. Meissner, G. Richter "The challenge to the automotive battery industry: the battery has to become an increasingly integrated component within the vehicle electric power system", Journal of Power Sources, vol. 144, 2005, pp. 438-460.

[12] K.V. Narayanaswamya, "Design and development of electrical energy management system for vehicle," International Journal of Current Engineering and Technology, vol. 3, No. 2, pp. 591-599, June 2013.

[13] R. Schöttle, G. Threin, "Electrical Power Supply Systems: present and future," VDI Berichte, pp. 449-475, 2000

[14] N.S. Zakharov, S.V. Elesin, O.A. Novoselov, S.J. Kichigin, A.N. Makarova, "Improving the efficiency of technical operation of the vehicles by optimizing the qualification structure of engineering servicing workers," International Journal of Applied Engineering Research, Vol. 11, № 3, pp. 1998-2006, 2016.

[15] N.S. Zakharov, A.A. Panfilov, "The influence of seasonal conditions on the heavy metals emissions during vehicle operation," Research Journal of Pharmaceutical, Biological and Chemical Sciences, Vol. 6, № 1, pp. 1838-1851, 2015. 